\title{
Corticofugal modulation of peripheral auditory responses
}

\author{
Gonzalo Terreros ${ }^{1}$ and Paul H. Delano ${ }^{1,2 *}$ \\ ${ }_{1}^{1}$ Programa de Fisiología y Biofísica, ICBM, Facultad de Medicina, Universidad de Chile, Santiago, Chile, ${ }^{2}$ Departamento de \\ Otorrinolaringología, Hospital Clínico de la Universidad de Chile, Santiago, Chile
}

The auditory efferent system originates in the auditory cortex and projects to the medial geniculate body (MGB), inferior colliculus (IC), cochlear nucleus (CN) and superior olivary complex (SOC) reaching the cochlea through olivocochlear (OC) fibers. This unique neuronal network is organized in several afferent-efferent feedback loops including: the (i) colliculo-thalamic-cortico-collicular; (ii) cortico-(collicular)-OC; and (iii) cortico-(collicular)-CN pathways. Recent experiments demonstrate that blocking ongoing auditory-cortex activity with pharmacological and physical methods modulates the amplitude of cochlear potentials. In addition, auditory-cortex microstimulation independently modulates cochlear sensitivity and the strength of the OC reflex. In this mini-review, anatomical and physiological evidence supporting the presence of a functional efferent network from the auditory cortex to the cochlear receptor is presented. Special emphasis is given to the corticofugal effects on initial auditory processing, that is, on $\mathrm{CN}$, auditory nerve and cochlear responses. A working model of three parallel pathways from the auditory cortex to the cochlea and auditory nerve is proposed.

Edited by: Jonathan B. Fritz, University of Maryland, USA

Reviewed by: Shihab Shamma, University of Maryland, USA Jun Yan,

University of Calgary, Canada

*Correspondence:

Paul H. Delano,

Programa de Fisiología y Biofísica, ICBM, Facultad de Medicina, Universidad de Chile, Independencia 1027, Santiago 8380453, Chile pdelano@med.uchile.cl

Received: 29 April 2015 Accepted: 15 September 2015 Published: 30 September 2015

Citation: Terreros G and Delano PH (2015) Corticofugal modulation of peripheral auditory responses.

Front. Syst. Neurosci. 9:134. doi: 10.3389/fnsys.2015.00134
Keywords: auditory efferent, olivocochlear, top-down, neural network, descending projections, corticofugal

\section{Introduction}

Since the first description of the crossed and uncrossed olivocochlear (OC) bundles by Rasmussen $(1946,1960)$, these brainstem pathways have been considered as the auditory efferent system itself, and the terms "olivocochlear" and "auditory efferent" have been frequently used as synonyms. However, several lines of neuroanatomical evidence demonstrate the presence of an efferent network originated in the auditory cortex that reaches the cochlear receptor through OC neurons (Feliciano et al., 1995; Mulders and Robertson, 2000). This network comprises descending projections from the auditory cortex to the medial geniculate body (MGB), inferior colliculus (IC), cochlear nucleus (CN) and superior olivary complex (SOC) that form multiple feedback loops, including the: (i) colliculo-thalamic-cortico-collicular; (ii) cortico-(collicular)-OC; and (iii) cortico-(collicular)-CN pathways (Saldaña et al., 1996; Robles and Delano, 2008; Xiong et al., 2009; Malmierca and Ryugo, 2011; Schofield, 2011).

The functionality of the corticofugal pathways to OC neurons has been proven by recent evidence demonstrating that auditory cortex activity can modulate afferent responses even at the level of sensory transduction (Xiao and Suga, 2002; León et al., 2012). Several functions have been attributed to these corticofugal effects on cochlear responses, including selective attention (Oatman, 1971), modulation of afferent inputs during wake/sleep cycle (Velluti et al., 1989) and antimasking of acoustic signals in noise background (Nieder and Nieder, 1970). It is important to highlight that any efferent modulation of the most peripheral structures of the auditory pathway - the auditory nerve and cochlear hair cells-must be mediated by the OC system. 
In this mini-review, anatomical and physiological evidence supporting the presence of a functional efferent network from the auditory cortex to the cochlear receptor are presented. Special emphasis is given to the corticofugal effects on $\mathrm{CN}$, auditory nerve and cochlear responses produced by auditory cortex manipulations. A working model of three parallel pathways from the auditory cortex to the cochlea and auditory nerve is proposed.

\section{The Olivocochlear System: the Final and Mandatory Pathway from the Central Nervous System to the Cochlear Receptor}

The OC system comprises medial (MOC) and lateral (LOC) olivocochlear neurons located in the SOC (Warr and Guinan, 1979). MOC neurons have thick and myelinated axons that are mainly directed towards outer hair cells $(\mathrm{OHC})$ of the contralateral cochlea, while LOC neurons possess thin and unmyelinated fibers that make synapses with ipsilateral auditory nerve dendrites just beneath cochlear inner hair cells (Guinan, 1996). Similarly to alpha-motor neurons, MOC neurons release acetylcholine as their main neurotransmitter, and activate nicotinic receptors comprised by five $\alpha 9 / \alpha 10$ subunits located in OHCs (Elgoyhen et al., 1994, 2001). On the other hand, several neurotransmitters and neuromodulators are known to be released by LOC neurons, including acetylcholine, GABA, dopamine, dynorphines, encephalin, and CGRP (Eybalin, 1993). Importantly, for the central nervous system, MOC neurons are the final and mandatory pathway to regulate the mechanical vibrations of the basilar membrane, acting as individual motor units along the cochlear partition (LePage, 1989; Murugasu and Russell, 1996; Cooper and Guinan, 2003). Therefore, the OC system is fundamental in the functioning of the efferent network, as all cortical or subcortical modulations of cochlear and auditory nerve responses must be transmitted through MOC or LOC synapses.

The OC function can be evaluated through a brainstem reflex that is activated by ipsilateral or contralateral auditory stimulation (Buño, 1978; Liberman, 1989). The neural circuit of this reflex is constituted by auditory nerve fibers, $\mathrm{CN}$ neurons, and crossed or uncrossed MOC fibers (de Venecia et al., 2005). The ipsilateral MOC reflex pathway comprises a double crossing, including the afferent pathway from the $\mathrm{CN}$ and the crossed MOC fibers, while the contralateral MOC reflex comprises only one crossing in the ascending pathway and the uncrossed MOC fibers. There is also anatomical evidence showing differences in the cochlear innervation patterns of crossed and uncrossed MOC fibers (Brown, 2014), which is in agreement with physiological data obtained in humans, that suggest different functions for the crossed and uncrossed MOC reflex (Lilaonitkul and Guinan, 2009). In addition, indirect LOC stimulation through IC descending pathways modulates the amplitude of auditory nerve responses (Groff and Liberman, 2003). Therefore, the OC system can modulate OHC and auditory nerve responses through three different pathways: (i) the crossed; (ii) uncrossed MOC fibers; and (iii) LOC neurons.

\section{Descending Projections from the Auditory Cortex to the Medial Geniculate Body}

Among the auditory subcortical nuclei, the MGB receives the largest number of cortical descending projections from pyramidal neurons located in layers V and VI of the auditory cortex, forming tonotopic feedback loops between the primary auditory cortex and ventral MGB (Bartlett et al., 2000; Winer et al., 2001; Winer, 2006; Winer and Lee, 2007). Physiological studies demonstrate that the auditory cortex modulates MGB responses (Ryugo and Weinberger, 1976; Villa et al., 1991; Zhang and Suga, 2000; Antunes and Malmierca, 2011), and that this modulation is different for ventral and medial MGB neurons (Tang et al., 2012). The electrical microstimulation of the auditory cortex produced sharply tuned effects in the ventral MGB, while suppressive and broad-band effects were obtained in the medial MGB. However, whether the corticofugal modulation of thalamic neurons affects OC activity is unknown. Importantly, as there is no anatomical evidence of direct descending connections from MGB to OC neurons, any possible thalamic modulation of OC activity should be produced indirectly through the colliculo-thalamic-cortico-collicular loop.

\section{Descending Projections from the Auditory Cortex to the Inferior Colliculus, Superior Olivary Complex and Cochlear Nucleus}

The IC is a key structure of the ascending and descending auditory pathways (Huffman and Henson, 1990). Direct descending projections from the auditory cortices to the IC are mainly originated in layer $\mathrm{V}$ of the primary fields, and in a lesser extent from layer VI (Faye-Lund, 1985; Doucet et al., 2003). Most of the cortico-collicular fibers are glutamatergic (Feliciano and Potashner, 1995) and are directed to the ipsilateral IC, but there are also fibers directed to the contralateral IC (Bajo et al., 2007; Nakamoto et al., 2013a,b). Although the majority of corticocollicular descending projections are directed to the IC cortices, a small subset reaches the central nucleus of the IC, which is the main ascending and tonotopic structure of this nucleus (Saldaña et al., 1996; Bajo and Moore, 2005). In agreement with these neuroanatomical findings, physiological evidence demonstrates a tonotopic modulation of the central nucleus of the IC by auditory cortex microstimulation (Yan and Suga, 1998; Yan et al., 2005). In addition, IC responses to sound intensity (Yan and Ehret, 2002), duration (Ma and Suga, 2001) and location (Zhou and Jen, 2005) are also modulated by the auditory cortex. More comprehensive reviews about the corticofugal effects on IC responses can be found elsewhere (Anderson and Malmierca, 2013; Bajo and King, 2013; Malmierca et al., 2015).

The SOC and the $\mathrm{CN}$ are also direct targets of cortical descending projections, mainly from primary auditory cortex, but also from ventral and rostral secondary fields (Weedman and Ryugo, 1996a,b; Doucet et al., 2002). Moreover, Mulders and Robertson showed evidence of the presence of synaptic connections between cortical descending axons and MOC neurons (Mulders and Robertson, 2000). There is also evidence 
of indirect connections between the auditory cortex and SOC through IC synapses (Thompson and Thompson, 1993; Vetter et al., 1993). Despite these neuroanatomical findings, there is still no physiological evidence of how the auditory cortex modulates the activity of SOC neurons. Regarding connections from the auditory cortex to the $\mathrm{CN}$, Schofield and colleagues have demonstrated that the dorsal and ventral $\mathrm{CN}$ receive direct projections from the auditory cortex, as well as indirect projections, passing through the IC or the SOC (Schofield and Cant, 1999; Schofield and Coomes, 2005; Schofield et al., 2006). In summary, descending projections from the auditory cortex to the IC, SOC and CN create multiple feedback loops that can modulate cochlear responses through OC neurons (Figure 1).

\section{Corticofugal Effects on Cochlear Nucleus}

The first evidence of a feedback control of $\mathrm{CN}$ responses by the central nervous system was found several decades ago in physiological experiments performed in awake and behaving cats (Hernández-Peón et al., 1956; Dewson et al., 1966). Hernández-Peón et al. (1956) found a reduction in the evoked potentials recorded from the $\mathrm{CN}$ in cats while

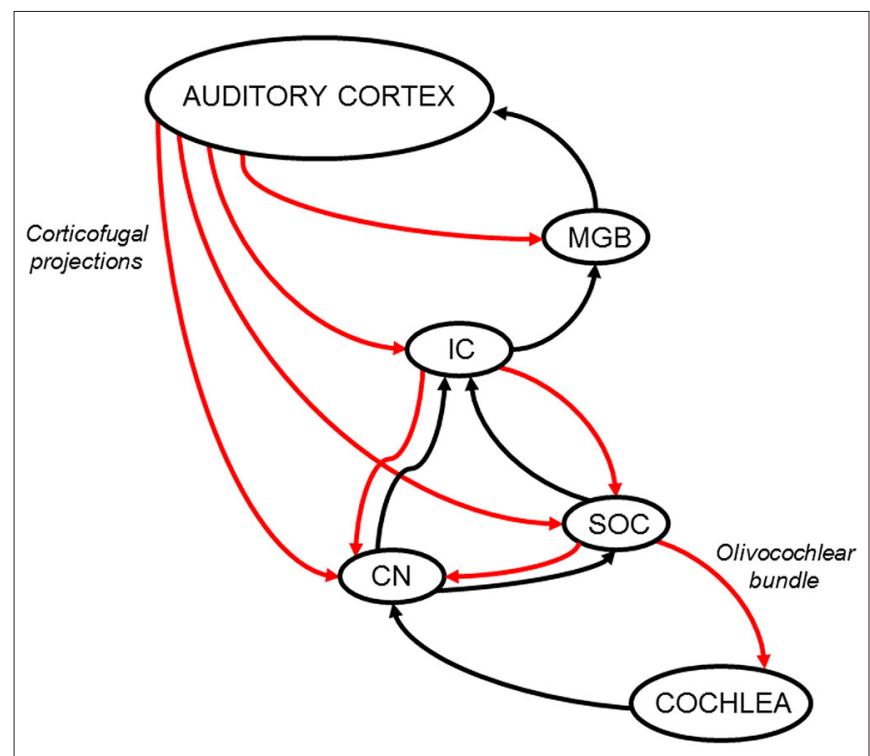

FIGURE 1 | Schematic diagram of the auditory efferent network. Ascending and descending pathways are depicted in black and red arrows respectively. A simplified model of the auditory efferent system is presented. Corticofugal projections from the auditory cortex to the inferior colliculus (IC) and medial geniculate body (MGB) and afferent connections from the IC and MGB to the auditory cortex form a "top loop" within this network (colliculo-thalamic-cortico-collicular loop, Xiong et al., 2009). Bottom loops are constituted by auditory-cortex descending projections to the $\mathrm{CN}$ (cortico-(collicular)-cochlear nucleus loop) and SOC (cortico-(collicular)olivocochlear loop), which are connected to the cochlear receptor by the OC bundle. Note, the relevant position of the IC in the interaction between top and bottom loops. In addition, it is important to highlight that cortical modulations of cochlear responses, can modify IC responses through ascending connections to the $\mathrm{CN}$ and $\mathrm{IC}$, meaning that the interaction between the top and bottom loops is bidirectional. CN: cochlear nucleus; IC: inferior colliculus; MGB: medial geniculate body; SOC: superior olivary complex. receiving stimuli of other sensory modalities. Later, Dewson et al. (1966) showed that auditory cortex ablations modified the evoked responses of the $\mathrm{CN}$. These pioneer studies suggested the presence of corticofugal pathways from the auditory cortex to the $\mathrm{CN}$ that were discovered several decades later (Weedman and Ryugo, 1996a,b; Schofield and Coomes, 2005, 2006).

The functionality of these pathways has been recently confirmed by studying the effects of electrical microstimulation of the auditory cortex in the contralateral $\mathrm{CN}$ of mice (Luo et al., 2008). These authors found that focal stimulation of a specific area of the auditory cortex increased the magnitudes and shortened the latencies of the responses of ventral $\mathrm{CN}$ neurons that had similar characteristic frequencies to the stimulated cortical site, while opposite effects were observed for $\mathrm{CN}$ neurons with other characteristic frequencies (Luo et al., 2008). Moreover, they found similar results in the ipsilateral ventral CN (Liu et al., 2010) and in the dorsal CN (Kong et al., 2014). These physiological studies are illustrative of a general characteristic of the efferent system: the frequency selectivity of corticofugal projections, which has also been obtained activating the descending pathways to the MGB, IC and cochlea (Suga and Ma, 2003).

\section{Corticofugal Effects on Auditory-Nerve and Cochlear Responses}

Only a few physiological studies have assessed the corticofugal effects of auditory cortex manipulations on the most peripheral auditory structures, including, auditory nerve responses (León et al., 2012; Dragicevic et al., 2015), cochlear electrical responses (Xiao and Suga, 2002; León et al., 2012; Dragicevic et al., 2015) and otoacoustic emissions (OAE; Khalfa et al., 2001; Perrot et al., 2006). In a seminal work, Xiao and Suga (2002) demonstrated that the auditory cortex activity modulates the amplitude and frequency tuning of cochlear microphonics (CM) responses near the echolocalizing frequency of the mustached bat (61 $\mathrm{kHz}$ ). In addition, corticofugal effects on cochlear responses have been found in human patients with epilepsy refractory to pharmacological treatment. In these patients, cortical resection of the temporal superior gyrus produced a bilateral reduction of the MOC reflex that was more pronounced in the ear contralateral to the resected auditory cortex (Khalfa et al., 2001). Moreover, electrical microstimulation of the auditory cortex by means of a chronic intra-cerebral multielectrode array produced a significant reduction of OAE, while there was no change under stimulation of non-auditory cortical areas (Perrot et al., 2006).

A recent work by León et al. (2012) extended the findings of the corticofugal effects observed in bats and humans to the chinchilla. In this work the spontaneous activity of the auditory cortex was inactivated by two methods: cortical cooling with cryoloops and lidocaine microinjections. The combined experimental approaches and the adequate control of the cochlear temperature ruled out the possibility of a direct cooling of the cochlea by the cortical cryoloops, as it has 
been suggested in guinea pigs by Coomber et al. (2011). Both types of cortical manipulations produced changes in the amplitudes of auditory-nerve compound action potentials (CAP) and CM responses (León et al., 2012). Although these effects were diverse, the most common pattern was a concomitant reduction in the amplitudes of CAP and CM responses. The electrical stimulation of the crossed MOC fibers at the floor of the fourth ventricle produces a decrease in CAP amplitudes and a simultaneous increase of CM responses (Gifford and Guinan, 1987). Therefore, the parallel changes of CAP and $\mathrm{CM}$ amplitudes observed in chinchillas after auditory cortex inactivation suggest a concomitant modulation of MOC and LOC neurons, as the latter system can only affect CAP but not CM responses (Groff and Liberman, 2003). León et al. (2012) proposed that the ongoing activity of the auditory cortex regulates cochlear sensitivity through parallel pathways to the cochlear receptor. However, whether these corticofugal effects were affecting the functioning of the OC reflex circuit remained unknown.

In a recent study, Dragicevic et al. (2015) used auditory cortex microstimulation in chinchillas to demonstrate that in addition to the corticofugal modulation of cochlear sensitivity on CAP and CM responses, the auditory cortex also modulates the strength of the contralateral OC reflex on CAP but not on $\mathrm{CM}$ responses. In agreement with neuroanatomical data, the largest corticofugal effects were obtained in auditory cortices with short latency responses $(<15 \mathrm{~ms})$, which correspond to primary auditory fields. Moreover, these two types of corticofugal modulations: (i) on cochlear sensitivity; and (ii) on the OC reflex strength were not correlated, suggesting the presence of at least two functionally different descending pathways to the crossed and uncrossed MOC neurons, and possibly a third pathway to LOC neurons (Figure 2). Some functional consequences of the corticofugal effects on the strength of the OC reflex could be the finding of stronger reflexes in awake than in anesthetized animals (Guitton et al., 2004; Chambers et al., 2012; Aedo et al., 2015), and the diminishing of tinnitus perception during stimulation of the auditory cortex in human patients (Fenoy et al., 2006; Fregni et al., 2006)

The model of three parallel descending pathways from the auditory cortex, is also supported by the presence of different types of projecting neurons, including regular and burst spiking pyramidal neurons from layer V (Hefti and Smith, 2000), and neurons from layer VI (Winer et al., 2001). Moreover, the differential corticofugal effects obtained with different microstimulation rates: $5 \mathrm{~Hz}$ to modulate IC and MGB responses (Suga and Ma, 2003) and $32-33 \mathrm{~Hz}$ to modulate SOC activity (Xiao and Suga, 2002; Dragicevic et al., 2015), suggest different activation thresholds for cortical neurons projecting to these subcortical nuclei.

\section{Functional Role of the Auditory Efferent System}

Different functions can be assigned to the different loops formed in the auditory efferent pathways. Functions mainly depending on the OC brainstem circuit are protection to acoustic trauma (Maison and Liberman, 2000) and balance of interaural cochlear sensitivity (Darrow et al., 2006), while neural plasticity during learning of behaviorally relevant auditory tasks has been attributed to the colliculo-thalamic-cortico-collicular loop (Xiong et al., 2009; Bajo et al., 2010). A top-down frequency filter needed in different behavioral situations can be proposed as the general function for the cortico-olivocochlear circuit, including selective attention to auditory or visual stimuli (Delano et al., 2007; Smith et al., 2012), regulation of afferent responses during wake/sleep cycle (Velluti et al., 1989; Froehlich et al., 1993), and antimasking of auditory stimuli in a noisy environment (Kawase and Liberman, 1993). As there is increasing evidence of the modulation of cochlear responses during selective attention, this putative function of the corticofugal system is discussed next.

\section{Selective Attention to Visual or Auditory Stimuli}

Since the early experiments performed in cats by HernándezPeón et al. (1956), the auditory efferent system has been proposed to function as a top-down filter of peripheral auditory responses during attention. To address this proposal, two types of attentional paradigms have been used: (i) attention to visual stimuli using irrelevant auditory distractors (Oatman, 1971; Delano et al., 2007), in which all peripheral auditory responses at all frequencies should be suppressed through the efferent system; and (ii) attention to auditory targets of specific frequency (Smith et al., 2012; Srinivasan et al., 2012), in which the peripheral auditory responses near the target frequency would be enhanced while other frequencies would be suppressed by the efferent system.

CAP reductions in response to click and tone auditory distractors during selective attention to visual stimuli have been obtained in cats and chinchillas (Oatman, 1971; Delano et al., 2007). In the latter work, CM increases concomitant to CAP reductions were obtained during visual attention, suggesting that these attentional effects were indeed produced by activation of MOC neurons, as the electrical stimulation of MOC fibers produces CAP reductions with simultaneous $\mathrm{CM}$ increases (Elgueda et al., 2011).

Contradictory results have been obtained in visual attention tasks with auditory distractors in humans. For instance, Puel et al. (1988) showed that click-evoked OAE were reduced in 13 out of 16 evaluated subjects during visual attention (1.25 $\mathrm{dB}$ in average). Similarly, Wittekindt et al. (2014) showed that during periods of visual attention to Gabor patches, there was a reduction in the amplitude of distortion product otoacoustic emissions (DPOAE). On the other hand, Smith and colleagues (Smith et al., 2012; Srinivasan et al., 2012), found a DPOAE increase during selective attention to visual stimuli, but a DPOAE reduction during auditory attention to the DPOAE primary tones $\left(f_{1}\right.$ and $f_{2}$ ). These opposite results could be explained by the differential generating mechanisms of click-evoked OAE with that of DPOAEs (Shera and Guinan, 1999). Importantly, in the work of Smith et al. (2012), subjects attended to the primary tones $\left(f_{1}\right.$ and $\left.f_{2}\right)$ that generate the DPOAEs, but measurements were 


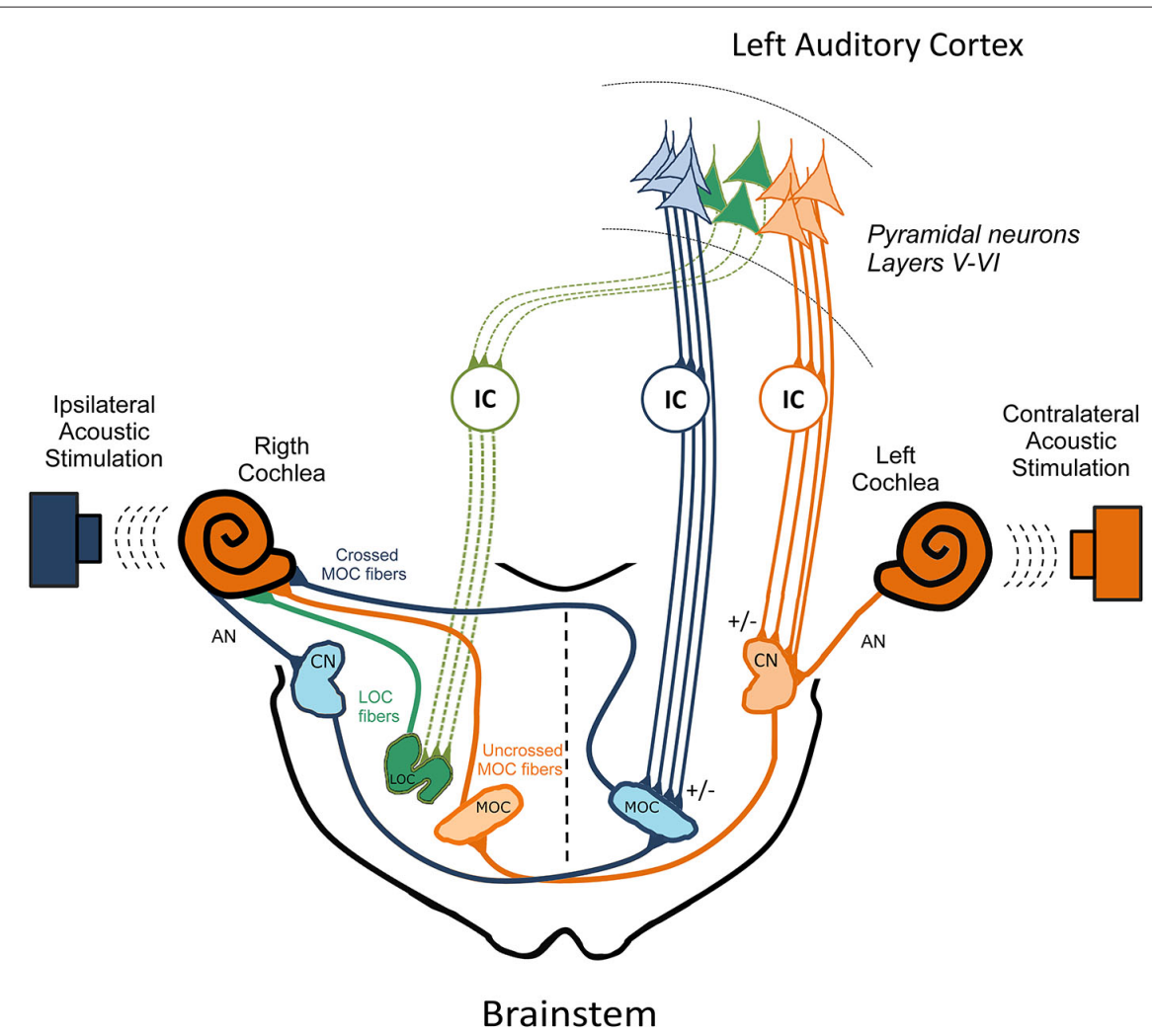

FIGURE 2 | The three pathways model for the cortico-collicular-olivocochlear and cochlear nucleus circuits. In order to simplify this model, the colliculo-thalamic-cortico-collicular loop has been omitted. In addition, only efferent pathways from the left auditory cortex to the right cochlea are presented. Three OC pathways are directed to the right cochlear receptor and auditory nerve, which are depicted in color green, orange and blue corresponding to the: (i) right LOC fibers; (ii) right uncrossed MOC; and (iii) left crossed MOC neurons respectively. Ipsilateral acoustic stimulation of the right cochlea activates right $\mathrm{AN}$, right $\mathrm{CN}$ neurons that send projections to the contralateral MOC. In turn, left crossed MOC neurons modulate right cochlear responses (blue brainstem pathways), constituting the ipsilateral OC reflex. On the other hand, contralateral acoustic stimulation of the left cochlea activates, left AN, left CN neurons that send projections to the right uncrossed MOC fibers, which modulate right cochlear responses (orange brainstem pathways), constituting the contralateral OC reflex that connects both ears. This model proposes that the descending pathways from the left auditory cortex directed to the left IC and to the left CN (orange corticofugal pathways) modulate the contralateral $\mathrm{OC}$ reflex, by regulating the activity of the left $\mathrm{CN}$ and right uncrossed MOC neurons. On the other hand, descending pathways directed to the left IC and left MOC (blue corticofugal pathways) regulate crossed MOC activity, which is involved in the ipsilateral OC reflex. Finally, corticofugal pathways to the contralateral IC (green corticofugal pathways) could regulate right LOC neurons, modulating the activity of right AN fibers. The +/- signs represent possible excitatory and inhibitory pathways. Modified from Dragicevic et al. (2015) with permission. AN: auditory nerve; CN: cochlear nucleus; LOC: lateral olivocochlear; MOC: medial olivocochlear; IC: inferior colliculus.

obtained from a distant location in the cochlear partition at the $2 \mathrm{f}_{1}-\mathrm{f}_{2}$ frequency. Future experiments should clarify whether the corticofugal effects are different if the subject attention is directed to the primary tones $\left(f_{1}\right.$ and $f_{2}$ ) or to the DPOAE frequency $\left(2 \mathrm{f}_{1}-\mathrm{f}_{2}\right)$.

Both ears are connected through the uncrossed MOC pathway that is activated by contralateral sounds (de Venecia et al., 2005). Notably, differential effects of interaural attention through uncrossed MOC fibers have been found in human studies (de Boer and Thornton, 2007; Srinivasan et al., 2014). Srinivasan et al. (2014) found that alternating auditory attention between the two ears modifies the strength of corticofugal effects on DPOAEs responses, suggesting that attention can independently modulate crossed and uncrossed MOC neurons. These findings are in agreement with the results obtained by Dragicevic et al. (2015) and support the model proposed in this article (Figure 2).

\section{Concluding Remarks}

In summary, here we reviewed the growing anatomical and physiological evidence supporting the presence of an efferent network from auditory cortex to OC neurons. Cortical descending effects on $\mathrm{CN}$, auditory nerve and cochlear responses are proposed to be produced by three parallel pathways from auditory cortex to the crossed and uncrossed MOC neurons and to LOC neurons. These connections are probably activated during selective attention, learning induced plasticity and other cognitive functions.

\section{Acknowledgments}

Supported by FONDECYT 3130635 and Fundación Guillermo Puelma. We thank Professor Luis Robles for his valuable comments. 


\section{References}

Aedo, C., Tapia, E., Pavez, E., Elgueda, D., Delano, P. H., and Robles, L. (2015). Stronger efferent suppression of cochlear neural potentials by contralateral acoustic stimulation in awake than in anesthetized chinchilla. Front. Syst. Neurosci. 9:21. doi: 10.3389/fnsys.2015.00021

Anderson, L. A., and Malmierca, M. S. (2013). The effect of auditory cortex deactivation on stimulus-specific adaptation in the inferior colliculus of the rat. Eur. J. Neurosci. 37, 52-62. doi: 10.1111/ejn.12018

Antunes, F. M., and Malmierca, M. S. (2011). Effect of auditory cortex deactivation on stimulus-specific adaptation in the medial geniculate body. J. Neurosci. 31, 17306-17316. doi: 10.1523/jneurosci.1915-11.2011

Bajo, V. M., and King, A. J. (2013). Cortical modulation of auditory processing in the midbrain. Front. Neural Circuits 6:114. doi: 10.3389/fncir.2012.00114

Bajo, V. M., and Moore, D. R. (2005). Descending projections from the auditory cortex to the inferior colliculus in the gerbil, Meriones unguiculatus. J. Comp. Neurol. 486, 101-116. doi: 10.1002/cne.20542

Bajo, V. M., Nodal, F. R., Bizley, J. K., Moore, D. R., and King, A. J. (2007). The ferret auditory cortex: descending projections to the inferior colliculus. Cereb. Cortex 17, 475-491. doi: 10.1093/cercor/bhj164

Bajo, V. M., Nodal, F. R., Moore, D. R., and King, A. J. (2010). The descending corticocollicular pathway mediates learning-induced auditory plasticity. Nat. Neurosci. 13, 253-260. doi: 10.1038/nn.2466

Bartlett, E. L., Stark, J. M., Guillery, R. W., and Smith, P. H. (2000). Comparison of the fine structure of cortical and collicular terminals in the rat medial geniculate body. Neuroscience 100, 811-828. doi: 10.1016/s0306-4522(00)00340-7

Brown, M. C. (2014). Single-unit labeling of medial olivocochlear neurons: the cochlear frequency map for efferent axons. J. Neurophysiol. 111, 2177-2186. doi: $10.1152 /$ jn.00045.2014

Buño, W. Jr. (1978). Auditory nerve fiber activity influenced by contralateral ear sound stimulation. Exp. Neurol. 59, 62-74. doi: 10.1016/0014-4886(78)90201-7

Chambers, A. R., Hancock, K. E., Maison, S. F., Liberman, M. C., and Polley, D. B. (2012). Sound-evoked olivocochlear activation in unanesthetized mice. J. Assoc. Res. Otolaryngol. 13, 209-217. doi: 10.1007/s10162-0110306-z

Coomber, B., Edwards, D., Jones, S. J., Shackleton, T. M., Goldschmidt, J., Wallace, M. N., et al. (2011). Cortical inactivation by cooling in small animals. Front. Syst. Neurosci. 5:53. doi: 10.3389/fnsys.2011.00053

Cooper, N. P., and Guinan, J. J. Jr. (2003). Separate mechanical processes underlie fast and slow effects of medial olivocochlear efferent activity. J. Physiol. 548, 307-312. doi: 10.1111/j.1469-7793.2003.00307.x

Darrow, K. N., Maison, S. F., and Liberman, M. C. (2006). Cochlear efferent feedback balances interaural sensitivity. Nat. Neurosci. 9, 1474-1476. doi: 10. $1038 / \mathrm{nn} 1807$

de Boer, J., and Thornton, A. R. (2007). Effect of subject task on contralateral suppression of click evoked otoacoustic emissions. Hear Res. 233, 117-123. doi: 10.1016/j.heares.2007.08.002

Delano, P. H., Elgueda, D., Hamame, C. M., and Robles, L. (2007). Selective attention to visual stimuli reduces cochlear sensitivity in chinchillas. J. Neurosci. 27, 4146-4153. doi: 10.1523/jneurosci.3702-06.2007

de Venecia, R. K., Liberman, M. C., Guinan, J. J. Jr., and Brown, M. C. (2005). Medial olivocochlear reflex interneurons are located in the posteroventral cochlear nucleus: a kainic acid lesion study in guinea pigs. J. Comp. Neurol. 487, 345-360. doi: 10.1002/cne.20550

Dewson, J. H. III, Nobel, K. W., and Pribram, K. H. (1966). Corticofugal influence at cochlear nucleus of the cat: some effects of ablation of insular-temporal cortex. Brain Res. 2, 151-159. doi: 10.1016/0006-8993(66) 90020-5

Doucet, J. R., Molavi, D. L., and Ryugo, D. K. (2003). The source of corticocollicular and corticobulbar projections in area Te1 of the rat. Exp. Brain Res. 153, 461-466. doi: 10.1007/s00221-003-1604-4

Doucet, J. R., Rose, L., and Ryugo, D. K. (2002). The cellular origin of corticofugal projections to the superior olivary complex in the rat. Brain Res. 925, 28-41. doi: 10.1016/s0006-8993(01)03248-6

Dragicevic, C. D., Aedo, C., León, A., Bowen, M., Jara, N., Terreros, G., et al. (2015). The olivocochlear reflex strength and cochlear sensitivity are independently modulated by auditory cortex microstimulation. J. Assoc. Res. Otolaryngol. 16, 223-240. doi: 10.1007/s10162-015-0509-9
Elgoyhen, A. B., Johnson, D. S., Boulter, J., Vetter, D. E., and Heinemann, S. (1994). Alpha 9: an acetylcholine receptor with novel pharmacological properties expressed in rat cochlear hair cells. Cell 79, 705-715. doi: 10.1016/00928674(94)90555-x

Elgoyhen, A. B., Vetter, D. E., Katz, E., Rothlin, C. V., Heinemann, S. F., and Boulter, J. (2001). Alpha10: a determinant of nicotinic cholinergic receptor function in mammalian vestibular and cochlear mechanosensory hair cells. Proc. Natl. Acad. Sci. U S A 98, 3501-3506. doi: 10.1073/pnas.051622798

Elgueda, D., Delano, P. H., and Robles, L. (2011). Effects of electrical stimulation of olivocochlear fibers in cochlear potentials in the chinchilla. J. Assoc. Res. Otolaryngol. 12, 317-327. doi: 10.1007/s10162-011-0260-9

Eybalin, M. (1993). Neurotransmitters and neuromodulators of the mammalian cochlea. Physiol. Rev. 73, 309-373.

Faye-Lund, H. (1985). The neocortical projection to the inferior colliculus in the albino rat. Anat. Embryol. (Berl). 173, 53-170. doi: 10.1007/bf00707304

Feliciano, M., and Potashner, S. J. (1995). Evidence for a glutamatergic pathway from the guinea pig auditory cortex to the inferior colliculus. J. Neurochem. 65, 1348-1357. doi: 10.1046/j.1471-4159.1995.65031348.x

Feliciano, M., Saldaña, E., and Mugnaini, E. (1995). Direct projections from the rat primary auditory neocortex to nucleus sagulum, paralemniscal regions, superior olivary complex and cochlear nuclei. Aud. Neurosci. 1, 287-308.

Fenoy, A. J., Severson, M. A., Volkov, I. O., Brugge, J. F., and Howard, M. A. 3rd (2006). Hearing suppression induced by electrical stimulation of human AC. Brain Res. 1118, 75-83. doi: 10.1016/j.brainres.2006.08.013

Fregni, F., Marcondes, R., Boggio, P. S., Marcolin, M. A., Rigonatti, S. P., Sanchez, G., et al. (2006). Transient tinnitus suppression induced by repetitive transcranial magnetic stimulation and transcranial direct current stimulation. Eur. J. Neurol. 13, 996-1001. doi: 10.1111/j.1468-1331.2006.01414.x

Froehlich, P., Collet, L., Valatx, J. L., and Morgon, A. (1993). Sleep and active cochlear micromechanical properties in human subjects. Hear. Res. 66, 1-7. doi: 10.1016/0378-5955(93)90254-x

Gifford, M. L., and Guinan, J. J. Jr. (1987). Effects of electrical stimulation of medial olivocochlear neurons on ipsilateral and contralateral cochlear responses. Hear. Res. 29, 179-194. doi: 10.1016/0378-5955(87)90166-3

Groff, J. A., and Liberman, M. C. (2003). Modulation of cochlear afferent response by the lateral olivocochlear system: activation via electrical stimulation of the inferior colliculus. J. Neurophysiol. 90, 3178-3200. doi: 10.1152/jn.00537.2003

Guinan, J. J. Jr. (1996). "Physiology of olivocochlear efferents," in The Cochlea, eds P. Dallos, A. Popper, and R. Fay (New York: Springer), 435-502.

Guitton, M. J., Avan, P., Puel, J. L., and Bonfils, P. (2004). Medial olivocochlear efferent activity in awake guinea pigs. Neuroreport 15, 1379-1382. doi: 10. 1097/01.wnr.0000131672.15566.64

Hefti, B. J., and Smith, P. H. (2000). Anatomy, physiology and synaptic responses of rat layer $\mathrm{V}$ auditory cortical cells and effects of intracellular GABA(A) blockade. J. Neurophysiol. 83, 2626-2638.

Hernández-Peón, R., Scherrer, H., and Jouvet, M. (1956). Modification of electric activity in cochlear nucleus during attention in unanesthetized cats. Science 123 , 331-332. doi: 10.1126/science.123.3191.331

Huffman, R. F., and Henson, O. W. Jr. (1990). The descending auditory pathway and acousticomotor systems: connections with the inferior colliculus. Brain Res. Brain Res. Rev. 15, 295-323. doi: 10.1016/0165-0173(90) 90005-9

Kawase, T., and Liberman, M. C. (1993). Antimasking effects of the olivocochlear reflex. I. Enhancement of compound action potentials to masked tones. J. Neurophysiol. 70, 2519-2532.

Khalfa, S., Bougeard, R., Morand, N., Veuillet, E., Isnard, J., Guenot, M., et al. (2001). Evidence of peripheral auditory activity modulation by the auditory cortex in humans. Neuroscience 104, 347-358. doi: 10.1016/s03064522(01)00072-0

Kong, L., Xiong, C., Li, L., and Yan, J. (2014). Frequency-specific corticofugal modulation of the dorsal cochlear nucleus in mice. Front. Syst. Neurosci. 8:125 doi: 10.3389/fnsys.2014.00125

León, A., Elgueda, D., Silva, M. A., Hamamé, C. M., and Delano, P. H. (2012). Auditory cortex basal activity modulates cochlear responses in chinchillas. PLoS One 7:e36203. doi: 10.1371/journal.pone.0036203

LePage, E. L. (1989). Functional role of the olivo-cochlear bundle: a motor unit control system in the mammalian cochlea. Hear Res. 38, 177-198. doi: 10. 1016/0378-5955(89)90064-6 
Liberman, M. C. (1989). Rapid assessment of sound-evoked olivocochlear feedback: suppression of compound action potentials by contralateral sound. Hear Res. 38, 47-56. doi: 10.1016/0378-5955(89)90127-5

Lilaonitkul, W., and Guinan, J. J. Jr. (2009). Human medial olivocochlear reflex: effects as functions of contralateral, ipsilateral and bilateral elicitor bandwidths. J. Assoc. Res. Otolaryngol. 10, 459-470. doi: 10.1007/s10162-009-0163-1

Liu, X., Yan, Y., Wang, Y., and Yan, J. (2010). Corticofugal modulation of initial neural processing of sound information from the ipsilateral ear in the mouse. PLoS One 5:e14038. doi: 10.1371/journal.pone.0014038

Luo, F., Wang, Q., Kashani, A., and Yan, J. (2008). Corticofugal modulation of initial sound processing in the brain. J. Neurosci. 28, 11615-11621. doi: 10. 1523/jneurosci.3972-08.2008

Ma, X., and Suga, N. (2001). Corticofugal modulation of duration-tuned neurons in the midbrain auditory nucleus in bats. Proc. Natl. Acad. Sci. U S A 98, 14060-14065. doi: 10.1073/pnas.241517098

Maison, S. F., and Liberman, M. C. (2000). Predicting vulnerability to acoustic injury with a noninvasive assay of olivocochlear reflex strength. J. Neurosci. 20, 4701-4707.

Malmierca, M. S., Anderson, L. A., and Antunes, F. M. (2015). The cortical modulation of stimulus-specific adaptation in the auditory midbrain and thalamus: a potential neuronal correlate for predictive coding. Front. Syst. Neurosci. 9:19. doi: 10.3389/fnsys.2015.00019

Malmierca, M. S., and Ryugo, D. K. (2011). "Descending connections of the auditory cortex to the midbrain and the brainstem," in The AC, eds J. A. Winer and C. E. Schreiner (New York: Springer Press), 189-208.

Mulders, W. H., and Robertson, D. (2000). Evidence for direct cortical innervation of medial olivocochlear neurones in rats. Hear. Res. 144, 65-72. doi: 10 . 1016/s0378-5955(00)00046-0

Murugasu, E., and Russell, I. J. (1996). The effect of efferent stimulation on basilar membrane displacement in the basal turn of the guinea pig cochlea. J. Neurosci. $16,325-332$.

Nakamoto, K. T., Mellott, J. G., Killius, J., Storey-Workley, M. E., Sowick, C. S., and Schofield, B. R. (2013a). Ultrastructural examination of the corticocollicular pathway in the guinea pig: a study using electron microscopy, neural tracers and GABA immunocytochemistry. Front. Neuroanat. 7:13. doi: 10.3389/fnana. 2013.00013

Nakamoto, K. T., Sowick, C. S., and Schofield, B. R. (2013b). Auditory cortical axons contact commissural cells throughout the guinea pig inferior colliculus. Hear. Res. 306, 131-144. doi: 10.1016/j.heares.2013. 10.003

Nieder, P., and Nieder, I. (1970). Antimasking effect of crossed olivocochlear bundle stimulation with loud clicks in guinea pig. Exp. Neurol. 28, 179-188. doi: 10.1016/0014-4886(70)90172-x

Oatman, L. C. (1971). Role of visual attention on auditory evoked potentials in unanesthetized cats. Exp. Neurol. 32, 341-356. doi: 10.1016/00144886(71)90003-3

Perrot, X., Ryvlin, P., Isnard, J., Guénot, M., Catenoix, H., Fischer, C., et al. (2006). Evidence for corticofugal modulation of peripheral auditory activity in humans. Cereb. Cortex 16, 941-948. doi: 10.1093/cercor/bhj035

Puel, J. L., Bonfils, P., and Pujol, R. (1988). Selective attention modifies the active micromechanical properties of the cochlea. Brain Res. 447, 380-383. doi: 10. 1016/0006-8993(88)91144-4

Rasmussen, G. L. (1946). The olivary peduncle and other fiber projections of the superior olivary complex. J. Comp. Neurol. 84, 141-219. doi: 10.1002/cne. 900840204

Rasmussen, G. L. (1960). "Efferent fibers of the cochlear nerve and cochlear nucleus," in Neural Mechanisms of the Auditory and Vestibular Systems, ed G. L. Rasmussen and W. F. Windle (Springfield, IL: Thomas), 105-115.

Robles, L., and Delano, P. H. (2008). "Efferent system," in The Senses: A Comprehensive Reference, eds P. Dallos and D. Oertel (London, UK: Academic Press), 413-445.

Ryugo, D. K., and Weinberger, N. M. (1976). Corticofugal modulation of the medial geniculate body. Exp. Neurol. 51, 377-391. doi: 10.1016/00144886(76)90262-4

Saldaña, E., Feliciano, M., and Mugnaini, E. (1996). Distribution of descending projections from primary auditory neocortex to inferior colliculus mimics the topography of intracollicular projections. J. Comp. Neurol. 371, 15-40. doi: 10. 1002/(sici)1096-9861(19960715)371:1<15::aid-cne2>3.0.co;2-o
Schofield, B. R. (2011). "Central descending auditory pathways," in Auditory and Vestibular Efferents, eds D. K. Ryugo, A. N. Popper, and R. R. Fay (New York, NY: Springer-Verlag), 261-290.

Schofield, B. R., and Cant, N. B. (1999). Descending auditory pathways: projections from the inferior colliculus contact superior olivary cells that project bilaterally to the cochlear nuclei. J. Comp. Neurol. 409, 210-223. doi: 10.1002/(sici)10969861(19990628)409:2<210::aid-cne3>3.0.co;2-a

Schofield, B. R., and Coomes, D. L. (2005). Auditory cortical projections to the cochlear nucleus in guinea pigs. Hear. Res. 199, 89-102. doi: 10.1016/j.heares. 2004.08.003

Schofield, B. R., and Coomes, D. L. (2006). Pathways from auditory cortex to the cochlear nucleus in guinea pigs. Hear. Res. 216-217, 81-89. doi: 10.1016/j. heares.2006.01.004

Schofield, B. R., Coomes, D. L., and Schofield, R. M. (2006). Cells in auditory cortex that project to the cochlear nucleus in guinea pigs. J. Assoc. Res. Otolaryngol. 7, 95-109. doi: 10.1007/s10162-005-0025-4

Shera, C. A., and Guinan, J. J. Jr. (1999). Evoked otoacoustic emissions arise by two fundamentally different mechanisms: a taxonomy for mammalian OAEs. J. Acoust. Soc. Am. 105, 782-798. doi: 10.1121/1.426948

Smith, D. W., Aouad, R. K., and Keil, A. (2012). Cognitive task demands modulate the sensitivity of the human cochlea. Front. Psychol. 3:30. doi: 10.3389/fpsyg. 2012.00030

Srinivasan, S., Keil, A., Stratis, K., Osborne, A. F., Cerwonka, C., Wong, J., et al. (2014). Interaural attention modulates outer hair cell function. Eur. J. Neurosci. 40, 3785-3792. doi: 10.1111/ejn.12746

Srinivasan, S., Keil, A., Stratis, K., Woodruff, K. L., and Smith, D. W. (2012). Effects of cross-modal selective attention on the sensory periphery: cochlear sensitivity is altered by selective attention. Neuroscience 223, 325-332. doi: 10 . 1016/j.neuroscience.2012.07.062

Suga, N., and Ma, X. (2003). Multiparametric corticofugal modulation and plasticity in the auditory system. Nat. Rev. Neurosci. 4, 783-794. doi: 10. 1038/nrn1222

Tang, J., Yang, W., and Suga, N. (2012). Modulation of thalamic auditory neurons by the primary auditory cortex. J. Neurophysiol. 108, 935-942. doi: 10.1152/jn. 00251.2012

Thompson, A. M., and Thompson, G. C. (1993). Relationship of descending inferior colliculus projections to olivocochlear neurons. J. Comp. Neurol. 335, 402-412. doi: 10.1002/cne.903350309

Velluti, R., Pedemonte, M., and García-Austt, E. (1989). Correlative changes of auditory nerve and microphonic potentials throughout sleep. Hear. Res. 39, 203-208. doi: 10.1016/0378-5955(89)90 091-9

Vetter, D. E., Saldaña, E., and Mugnaini, E. (1993). Input from the inferior colliculus to medial olivocochlear neurons in the rat: a double label study with PHA-L and cholera toxin. Hear. Res. 70, 173-186. doi: 10.1016/03785955(93)90156-u

Villa, A. E., Rouiller, E. M., Simm, G. M., Zurita, P., de Ribaupierre, Y., and de Ribaupierre, F. (1991). Corticofugal modulation of the information processing in the auditory thalamus of the cat. Exp. Brain Res. 86, 506-517. doi: 10. 1007/bf00230524

Warr, W. B., and Guinan, J. J. Jr. (1979). Efferent innervation of the organ of corti: two separate systems. Brain Res. 173, 152-155. doi: 10.1016/00068993(79)91104-1

Weedman, D. L., and Ryugo, D. K. (1996a). Pyramidal cells in primary auditory cortex project to cochlear nucleus in rat. Brain Res. 706, 97-102. doi: 10 . 1016/0006-8993(95)01201-x

Weedman, D. L., and Ryugo, D. K. (1996b). Projections from auditory cortex to the cochlear nucleus in rats: synapses on granule cell dendrites. J. Comp. Neurol. 371, 311-324. doi: 10.1002/(sici)1096-9861(19960722)371:2<311::aidcne $10>3.0 . \mathrm{co} ; 2-\mathrm{v}$

Winer, J. A. (2006). Decoding the auditory corticofugal systems. Hear. Res. 212, 1-8. doi: 10.1016/j.heares.2005.06.014

Winer, J. A., Diehl, J. J., and Larue, D. T. (2001). Projections of auditory cortex to the medial geniculate body of the cat. J. Comp. Neurol. 430, 27-55. doi: 10.1002/1096-9861(20010129)430:1<27::aid-cne1013>3 $0 . \operatorname{co} ; 2-8$

Winer, J. A., and Lee, C. C. (2007). The distributed auditory cortex. Hear. Res. 229, 3-13. doi: 10.1016/j.heares.2007.01.017 
Wittekindt, A., Kaiser, J., and Abel, C. (2014). Attentional modulation of the inner ear: a combined otoacoustic emission and EEG study. J. Neurosci. 34, 9995-10002. doi: 10.1523/JNEUROSCI.4861-13.2014

Xiao, Z., and Suga, N. (2002). Modulation of cochlear hair cells by the auditory cortex in the mustached bat. Nat. Neurosci. 5, 57-63. doi: 10.1038/ nn786

Xiong, Y., Zhang, Y., and Yan, J. (2009). The neurobiology of sound-specific auditory plasticity: a core neural circuit. Neurosci. Biobehav. Rev. 33, 1178-1184. doi: 10.1016/j.neubiorev.2008.10.006

Yan, J., and Ehret, G. (2002). Corticofugal modulation of midbrain sound processing in the house mouse. Eur. J. Neurosci. 16, 119-128. doi: 10.1046/j. 1460-9568.2002.02046.x

Yan, J., Zhang, Y., and Ehret, G. (2005). Corticofugal shaping of frequency tuning curves in the central nucleus of the inferior colliculus of mice. J. Neurophysiol. 93, 71-83. doi: 10.1152/jn.00348.2004

Yan, W., and Suga, N. (1998). Corticofugal modulation of the midbrain frequency map in the bat auditory system. Nat. Neurosci. 1, 54-58. doi: 10.1038/255
Zhang, Y., and Suga, N. (2000). Modulation of responses and frequency tuning of thalamic and collicular neurons by cortical activation in mustached bats. $J$. Neurophysiol. 84, 325-333.

Zhou, X., and Jen, P. H. (2005). Corticofugal modulation of directional sensitivity in the midbrain of the big brown bat, Eptesicus fuscus. Hear. Res. 203, 201-215. doi: 10.1016/j.heares.2004.12.008

Conflict of Interest Statement: The authors declare that the research was conducted in the absence of any commercial or financial relationships that could be construed as a potential conflict of interest.

Copyright (c) 2015 Terreros and Delano. This is an open-access article distributed under the terms of the Creative Commons Attribution License (CC BY). The use, distribution and reproduction in other forums is permitted, provided the original author(s) or licensor are credited and that the original publication in this journal is cited, in accordance with accepted academic practice. No use, distribution or reproduction is permitted which does not comply with these terms. 